\title{
Kaurene diterpene induces apoptosis in U87 human malignant glioblastoma cells by suppression of anti-apoptotic signals and activation of cysteine proteases
}

\author{
F.S. Lizarte Neto ${ }^{1}$, D.P.C. Tirapelli ${ }^{1}$, S.R. Ambrosio ${ }^{2}$, C.R. Tirapelli ${ }^{3}$, F.M. Oliveira ${ }^{4}$, \\ P.C. Novais ${ }^{1}$, F.M. Peria ${ }^{4}$, H.F. Oliveira ${ }^{4}$, C.G. Carlotti Junior ${ }^{1}$ and L.F. Tirapelli ${ }^{1}$
}

${ }^{1}$ Departamento de Cirurgia e Anatomia, Faculdade de Medicina de Ribeirão Preto, Universidade de São Paulo, Ribeirão Preto, SP, Brasil

${ }^{2}$ Núcleo de Pesquisa em Ciências e Tecnologia, Universidade de Franca, Franca, SP, Brasil ${ }^{3}$ Laboratório de Farmacologia, Departamento de Enfermagem Psiquiátrica e Ciências Humanas, Escola de Enfermagem de Ribeirão Preto, Universidade de São Paulo, Ribeirão Preto, SP, Brasil ${ }^{4}$ Departamento de Clínica Médica, Faculdade de Medicina de Ribeirão Preto, Universidade de São Paulo, Ribeirão Preto, SP, Brasil

\begin{abstract}
Gliomas are the most common and malignant primary brain tumors in humans. Studies have shown that classes of kaurene diterpene have anti-tumor activity related to their ability to induce apoptosis. We investigated the response of the human glioblastoma cell line U87 to treatment with ent-kaur-16-en-19-oic acid (kaurenoic acid, KA). We analyzed cell survival and the induction of apoptosis using flow cytometry and annexin V staining. Additionally, the expression of anti-apoptotic (c-FLIP and miR-21) and apoptotic (Fas, caspase-3 and caspase-8) genes was analyzed by relative quantification (real-time PCR) of mRNA levels in U87 cells that were either untreated or treated with KA $(30,50$, or $70 \mu \mathrm{M})$ for 24,48 , and $72 \mathrm{~h}$. U87 cells treated with KA demonstrated reduced viability, and an increase in annexin $\mathrm{V}$ - and annexin V/PI-positive cells was observed. The percentage of apoptotic cells was $9 \%$ for control cells, $26 \%$ for cells submitted to $48 \mathrm{~h}$ of treatment with $50 \mu \mathrm{M} \mathrm{KA}$, and $31 \%$ for cells submitted to $48 \mathrm{~h}$ of treatment with $70 \mu \mathrm{M}$ KA. Similarly, in U87 cells treated with KA for $48 \mathrm{~h}$, we observed an increase in the expression of apoptotic genes (caspase-8, -3) and a decrease in the expression of anti-apoptotic genes (miR-21 and $c$ $F L I P$ ). KA possesses several interesting properties and induces apoptosis through a unique mechanism. Further experiments will be necessary to determine if KA may be used as a lead compound for the development of new chemotherapeutic drugs for the treatment of primary brain tumors.
\end{abstract}

Key words: Kaurenoic acid; Glioblastoma; miR-21; c-FLIP; Apoptosis

\section{Introduction}

Gliomas are the most common and lethal malignant primary brain tumors in humans. Glioblastoma multiforme is the highest grade, the most aggressive and the most frequent glioma (1). Because gliomas are characterized by a diffuse infiltrative growth into the surrounding brain tissue, the complete surgical resection of glioblastoma multiforme tumors is virtually impossible (2). In addition, high-grade gliomas exhibit only limited sensitivity to multimodal treatment with radiotherapy and chemotherapy, which in large part is caused by the inherent and potent resistance of the tumor cells to apoptosis (3).
Clearly, overcoming apoptotic resistance through the reactivation of apoptosis in malignant cells will be important for the development of novel glioma therapies.

Recently, several natural products derived from plants have been reported to prevent tumorigenesis and suppress the growth of established tumors. Research has intensely focused on the identification of new herbal medicines and on the mechanisms behind the anti-tumor properties of existing natural products (4).

Many reports have extensively shown that kaurenetype diterpenes exert several biological activities. One

Correspondence: L.F. Tirapelli, Departamento de Cirurgia e Anatomia, FMRP, USP, Av. Bandeirantes, 3900, 14049-900 Ribeirão Preto, SP, Brasil. E-mail: tirapeli@fmrp.usp.br 
such kaurene-type diterpene, ent-kaur-16-en-19-oic acid (kaurenoic acid, KA), has been reported to have antimicrobial activity against Bacillus subtilis $(5,6)$, Staphylococcus aureus, Mycobacterium smegmatis $(5,7)$, Saccharomyces cerevisae, Escherichia coli, Cladosporium herbarium, and Candida albicans (5).

In addition to its antimicrobial and anti-parasitic activities, KA also exerts cytotoxic effects. Cytotoxic and anti-proliferative actions on tumor cell cultures (human breast cancer, human colon cancer and leukemia) have been described for this diterpene (8). Interestingly, Cavalcanti et al. (9) evaluated the potential genotoxicity of KA against Chinese hamster lung fibroblast (V79) cells in vitro. They found that $\mathrm{KA}$ failed to induce significant DNA damage and micronucleus frequencies at concentrations of $2.5,5$, and $10 \mu \mathrm{g} / \mathrm{mL}$; however, the exposure of V79 cells to higher concentrations of KA (30 and $60 \mu \mathrm{g} / \mathrm{mL}$ ) caused significant increases in the cell damage index and frequency. This study supports a dosedependent cytotoxic effect of KA on non-cancer cells.

Apoptosis, or programmed cell death, is a form of cell death that is defined by a characteristic set of morphological and biochemical changes. Apoptosis is a highly regulated process that involves the activation of a series of cellular events that ultimately lead to cell death. Apoptosis plays an important role in the inhibition of cancer development, and impaired apoptosis is now recognized to be a key step in tumorigenesis (10). The activation of apoptotic pathways is a key mechanism by which cytotoxic drugs kill tumor cells $(10,11)$. Indeed, the induction of apoptosis is now considered to be an important method for the assessment of the clinical effectiveness of many anti-tumor drugs and is a significant index used for the selection of new anti-tumor drugs $(12,13)$.

MicroRNAs (miRNAs) are small ( $\sim 20-22$ nucleotides) non-coding RNAs that bind to complementary recognition sequences in mRNA, causing either mRNA degradation or the inhibition of translation. Thus, miRNAs are capable of effectively silencing their mRNA targets. This pretranslational control is estimated to affect up to one-third of all human transcripts, including transcripts that are involved in cancer (14). Recently, microRNA-21 (miR-21) was shown to be strongly overexpressed in glioblastoma tumors and cell lines. In the same study, the inhibition of miRNA-21 by a locked nucleic acid led to increased caspase-dependent apoptosis, suggesting that miR-21 could be acting as an oncogene by inhibiting apoptosis in glioma cells (15).

Although studies have shown that classes of kaurene diterpene have anti-tumor activity due to the induction of apoptosis, there are no data in the literature regarding the action of KA on glioma tumor cells. Here, we address this shortcoming by evaluating the cellular responses of the U87 human glioblastoma cell line to KA treatment. We examined cell survival, the induction of apoptosis via the flow cytometric analysis of annexin $\mathrm{V}$ staining, miR-21 gene expression and the expression of anti-apoptotic (cFLIP) and apoptotic (Fas, caspase-8 and caspase-3) genes that are known to be associated with the extrinsic pathway of apoptosis.

\section{Material and Methods}

\section{Procedure for KA isolation}

Certified dried leaves of Mikania hirsutissima $(1.0 \mathrm{~kg})$ were purchased from Nutri Comércio de Ervas Ltda. (Brazil). The plant material was pulverized and dichloromethane $(3.5 \mathrm{~L})$ was exhaustively extracted at room temperature to yield $42.0 \mathrm{~g}$ crude extract. This extract was suspended in $300 \mathrm{~mL}$ methanol- $\mathrm{H}_{2} \mathrm{O}$ (9:1) and filtered. The soluble fraction was partitioned using $n$ hexane (300 mL, partitioned 4 times). The solvent was evaporated under reduced pressure, resulting in $6.0 \mathrm{~g}$ of a hexane-soluble fraction.

The $n$-hexane-soluble fraction was chromatographed over a Si gel 60 column (0.063-0.200 mm) using vacuum chromatography with $n$-hexane, and increasing amounts of ethyl acetate were used for elution (16). This procedure yielded 12 fractions of $250 \mathrm{~mL}$ each. The second fraction (1730.0 mg) was washed with cold methanol to yield entkaur-16-en-19-oic acid (KA; 800.0 mg; Figure 1). The purity of KA was estimated by thin-layer chromatography using different solvent systems. Moreover, KA was also submitted to ${ }^{1} \mathrm{H}$ and ${ }^{13} \mathrm{C}$ nuclear magnetic resonance spectral data analysis, which indicated that the purity grade was between 95 and $98 \%$.

\section{Cell culture}

The U87 human glioblastoma cell line (ATCC, USA) was cultured in Dulbecco's modified Eagle's medium (Sigma, USA) supplemented with $10 \%$ heat-inactivated bovine serum, $100 \mathrm{U} / \mathrm{mL}$ penicillin and $50 \mu \mathrm{g} / \mathrm{mL}$ streptomycin/neomycin in a humidified incubator at $37^{\circ} \mathrm{C}$ and $5 \%$ carbon dioxide. All experimental procedures were approved by the Research Ethics Committee of Hospital

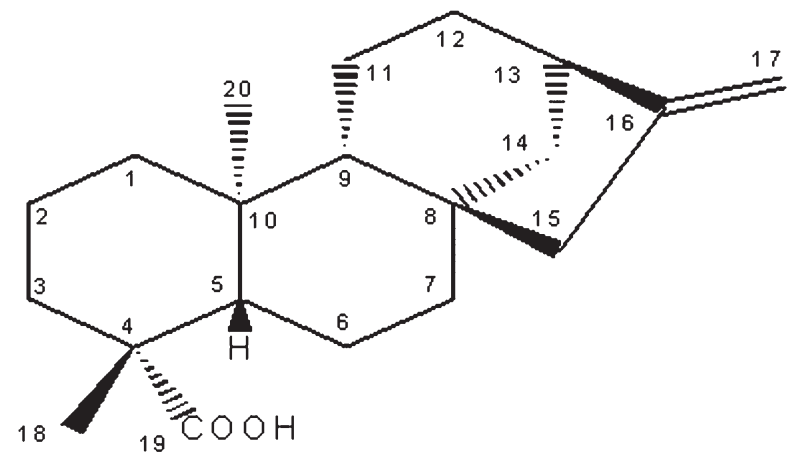

Figure 1. Structure of ent-kaur-16-en-19-oic acid (kaurenoic acid, $K A)$. 
das Clínicas, Faculdade de Medicina de Ribeirão Preto, Universidade de São Paulo (protocol No. 3506/09).

\section{Cell treatments}

Experiments were carried out using cells grown on 6well culture plates (TPP-Techno Plastic Products AG, Switzerland). The U87 glioma cell line was seeded at a density of $1 \times 10^{5}$ cells/well. After $24 \mathrm{~h}$, the medium was removed, and $2 \mathrm{~mL}$ of a KA-Dulbecco's modified Eagle's medium was added to each well. KA was used at concentrations of 30,50 , or $70 \mu \mathrm{M}$. The treated cells were returned to the incubator and kept at $37^{\circ} \mathrm{C}$ with $5 \%$ carbon dioxide for 24,48 , or $72 \mathrm{~h}$. The cells were subsequently used in the assays described below. The concentrations of KA used in the present study were as previously described, and did not induce genotoxicity in Chinese hamster lung fibroblast (V79) cells (9).

\section{Cell viability assay}

Cell viability was assessed using the trypan blue dyeexclusion method. Briefly, cells were treated with different concentrations of $\mathrm{KA}$ and collected. Equal volumes of a trypan blue solution were then added to the cells. After a 15- to 20-min incubation at room temperature, the cells were counted using a hemocytometer. The ratio of viable cells to the total number of cells was calculated and recorded.

\section{Annexin $\mathbf{V}$ and propidium iodide (PI) staining}

Apoptosis was detected using an annexin V/PI detection assay $(17,18)$. Briefly, U87 cells were treated with different concentrations of KA. After $48 \mathrm{~h}$, the cells were analyzed by flow cytometry (FACScan, Becton Dickinson, USA) according to manufacturer instructions (annexin V-FITC apoptosis kit, BD Biosciences, USA). Data were further analyzed with the CELLQuest software (Becton Dickinson). The experiments were performed in serum-free medium.

\section{RNA isolation and real-time polymerase chain reaction (PCR)}

The Trizol reagent (Applied Biosystems, USA) was used according to manufacturer instructions to extract total RNA from cells that had been treated with different concentrations of KA. To prepare the real-time PCR, reverse transcription of the RNA samples was performed using the High-Capacity cDNA kit (Applied Biosystems). Real-time PCR analysis of the CDNA samples was performed at $95-60^{\circ} \mathrm{C}$ for 45 cycles in the $\mathrm{ABI}$ Prism 7300 sequence detection system (Applied Biosystems) according to manufacturer instructions. We used the Taqman reaction master mix (Applied Biosystems) and the following primers: FAS (Assay ID Hs00163653_m1), c-FLIP (Assay ID Hs01116280_m1), caspase-8 (Assay ID Hs01018156_m1), and caspase-3 (Assay ID Hs00234385_m1). The comparative cycle time (Ct) method was used to calculate the relative abundance of miR-21 compared to $\beta$-actin (Assay ID Hs99999903_m1).

To determine the expression level of miR-21, total RNA was extracted with Trizol from cells that were either untreated or treated with $70 \mu \mathrm{M} \mathrm{KA}$ for $72 \mathrm{~h}(5.0 \mathrm{ng} /$ reaction). The RNA was reverse-transcribed using reagents from the High Capacity C-DNA Archive Kit (Applied Biosystems), 3.8 U RNase inhibitor (Applied Biosystems), and the specific looped RT primer for miR21 , which was provided in the assay kit. The samples were incubated for $30 \mathrm{~min}$ at $16^{\circ} \mathrm{C}, 30 \mathrm{~min}$ at $42^{\circ} \mathrm{C}$, and $5 \mathrm{~min}$ at $85^{\circ} \mathrm{C}$. Samples were then held at $4^{\circ} \mathrm{C}$. Real-time PCR analysis of the cDNA samples was performed at $95^{\circ} \mathrm{C}$ for 10 min followed by 40 cycles in the $A B I$ Prism 7300 sequence detection system (Applied Biosystems) according to manufacturer instructions. We used the Taqman reaction master mix (Applied Biosystems) and the hsa-mir21 (Hsa-mir21 003438) primer. The comparative $\mathrm{Ct}$ method was used to calculate the relative abundance of miR-21 compared to RNU24 (Assay ID 001001).

\section{Statistical analysis}

Data are reported as means \pm SE. For statistical comparisons, the New Instat program (Graph pad-Instat, USA) was used to perform the $t$-test or one-way ANOVA followed by the Bonferroni test. $P$ values of less than 0.05 were considered to be statistically significant.

\section{Results}

\section{Cell viability assay}

U87 cells were treated with three selective doses of $\mathrm{KA}$ to examine the efficacy of the compound in decreasing cell viability and inducing apoptosis. Residual cell viability was determined with the trypan blue exclusion dye test using light microscopy, and viability was assessed after treatment of the cells with 30,50 , or $70 \mu \mathrm{M} \mathrm{KA}$ at time intervals of 24,48 , and $72 \mathrm{~h}$. As shown in Figure 2, KA significantly decreased cell viability in U87 cells in a doseand time-dependent manner. U87 cells treated with $30 \mu \mathrm{M} \mathrm{KA}$ did not show reduced cell viability; however, at $50 \mu \mathrm{M} \mathrm{KA}$, a decrease in cell viability was observed upon comparison of the 24 and $72 \mathrm{~h}$ time points $(\mathrm{P}<$ 0.05). At $70 \mu \mathrm{M} \mathrm{KA}$, a decrease in cell viability was observed upon comparison of the 24 and $48 \mathrm{~h}, 24$ and $72 \mathrm{~h}$, and 48 and $72 \mathrm{~h}$ time points $(\mathrm{P}<0.05)$.

\section{KA-induced apoptosis of U87 cells}

The externalization of phosphatidylserine, which is a hallmark of apoptotic cells, has also been observed in alternative types of programmed cell death. To determine whether such processes were induced upon KA treatment, $U 87$ cells were treated for 24,48 , and $72 \mathrm{~h}$ with 30 , 50 , or $70 \mu \mathrm{M} \mathrm{KA}$. The annexin $\mathrm{V} / \mathrm{PI}$ assay revealed that the number of annexin $\mathrm{V}$ - and annexin V/PI-positive cells 


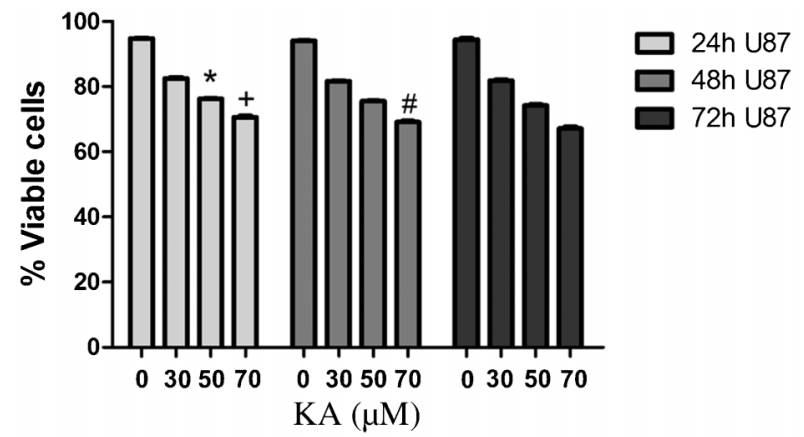

Figure 2. Effect of kaurenoic acid (KA) treatment on cell viability. U87 cells were treated with different concentrations of KA, and the trypan blue dye-exclusion method was used to detect cell viability. The $y$-axis shows the percentage of cell viability. The concentrations of KA used and the durations of the treatments are indicated. Data are reported as means \pm SD of 3 determinations. ${ }^{*} \mathrm{P}<0.05$ for $50 \mu \mathrm{M} \mathrm{KA}: 24$ compared to $72 \mathrm{~h}$; ${ }^{+} \mathrm{P}<0.05$ for $70 \mu \mathrm{M}$ KA: 24 compared to 48 and $72 \mathrm{~h}$; ${ }^{\#} \mathrm{P}<0.05$ for $70 \mu \mathrm{M}$ KA: 48 compared to $72 \mathrm{~h}$ (Bonferroni multiple comparison test). increased after $48 \mathrm{~h}$ of treatment with 50 and $70 \mu \mathrm{M} \mathrm{KA}$. The percentages of apoptotic cells were 9,26 , and $31 \%$ for control cells, cells submitted to $48 \mathrm{~h}$ of treatment with $50 \mu \mathrm{M} \mathrm{KA}$, and cells submitted to $48 \mathrm{~h}$ of treatment with $70 \mu \mathrm{M}$ KA, respectively $(\mathrm{P}<0.05$; Figure 3 ).

Fas, caspase- 3 and caspase- 8 mRNA expression in glioblastoma cells after treatment with KA for 24, 48, and $72 \mathrm{~h}$

The expression of apoptotic (Fas, caspase-8, caspase-3) and anti-apoptotic (c-FLIP) genes was analyzed by quantifying the relative mRNA levels in U87 human glioblastoma cells that had been left untreated or were treated with different concentrations of KA for 24, 48, and $72 \mathrm{~h}$. Among the apoptotic genes studied, no significant difference in Fas gene expression was observed between untreated cells and cells treated with KA for $48 \mathrm{~h}$ (data not shown).

As mentioned above, no significant differences were observed in the expression of apoptotic (Fas, caspase-8 and caspase-3) and anti-apoptotic (c-FLIP) genes
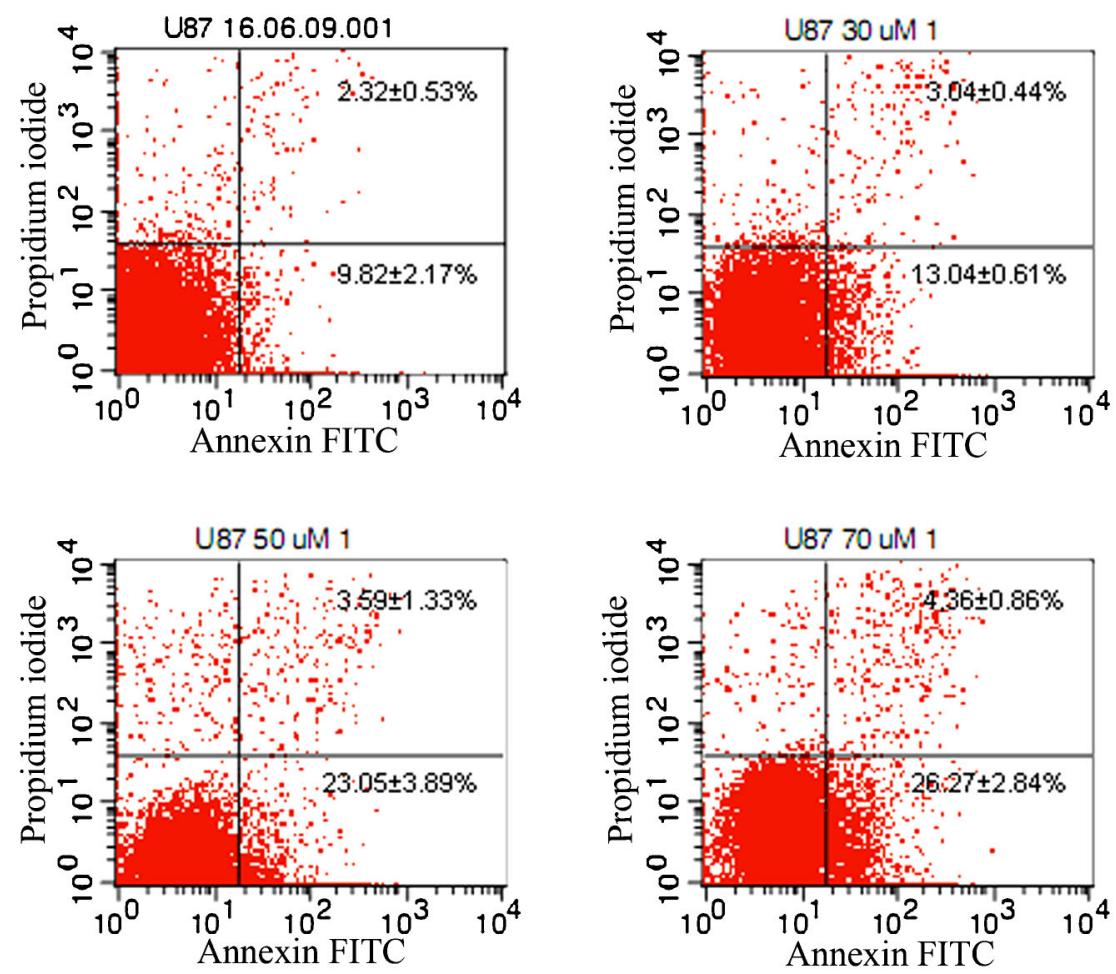

Figure 3. Kaurenoic acid (KA) induces apoptosis in U87 cells. U87 cells were treated with 30,50 , or $70 \mu \mathrm{M}$ KA for $48 \mathrm{~h}$. Phosphatidylserine (PS) externalization was determined by the combined annexin V/propidium iodide (PI) assay. Cells that stained positive for annexin $V$ represented cells with intact membranes and externalized PS (percentages are indicated in the lower right panel). Cells that stained positive for annexin V/PI represent cells that had lost membrane integrity (percentages are indicated in the upper right panel). Data are reported as means \pm SD of 3 determinations. $\mathrm{P}<0.05$ for 70 and $50 \mu \mathrm{M}$ KA treatment vs control (Bonferroni multiple comparison test). 

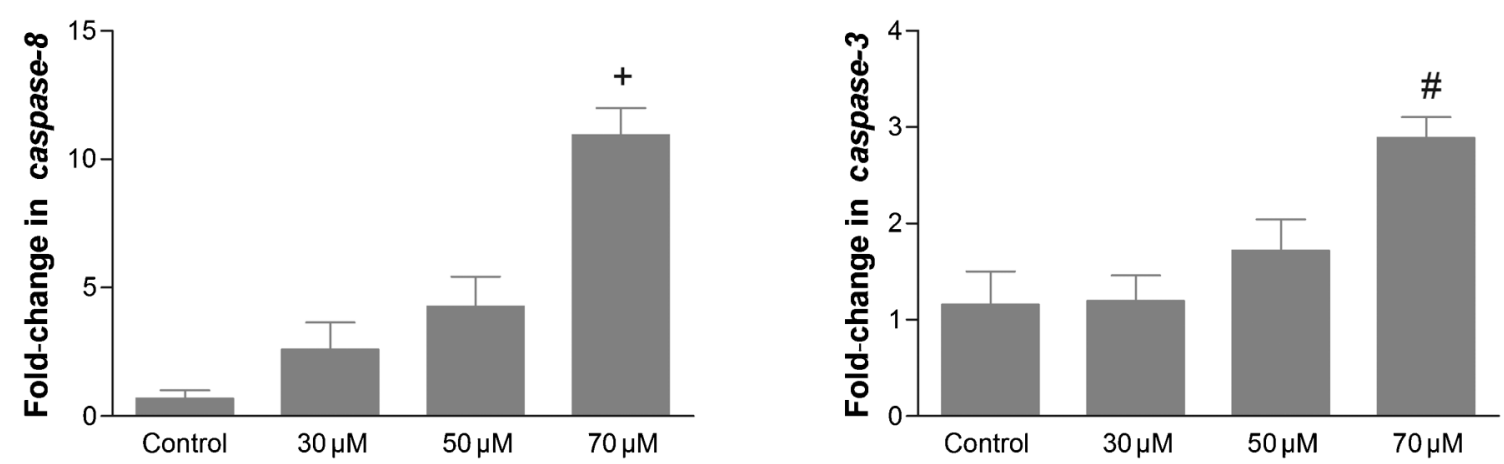

Figure 4. Caspase-3 and caspase- 8 gene expression in U87 cells. The $y$-axis indicates the fold-change in caspase- 3 and caspase-8 expression. Data are reported as means \pm SD for 3 measurements. The expression levels of caspase- 3 and caspase- 8 were compared between cells that had been treated with different concentrations of kaurenoic acid (KA) for $48 \mathrm{~h}$ and untreated cells. ${ }^{\mathrm{P}}<$ 0.0001 for $70 \mu \mathrm{M}$ KA treatment vs control cells for caspase-3. ${ }^{+} \mathrm{P}<0.001$ for $70 \mu \mathrm{M} \mathrm{KA}$ treatment vs control cells for caspase-8 (Bonferroni multiple comparison test).

between untreated U87 cells and cells treated with KA for 24 and $72 \mathrm{~h}$ (data not shown); however, in comparison to the U87 control cells, high expression of caspase-3 and caspase- 8 were observed in cells treated with $70 \mu \mathrm{M} \mathrm{KA}$ for $48 \mathrm{~h}$ ( $\mathrm{P}<0.001$ for caspase-3 and $\mathrm{P}<0.0001$ for caspase-8; Figure 4). Moreover, the expression of c-FLIP, a regulator of apoptosis, was decreased in U87 cells treated with 50 or $70 \mu \mathrm{M} \mathrm{KA}$ for $48 \mathrm{~h}$ in comparison to untreated cells $(P<0.05$; Figure 5$)$.

\section{miR-21 levels in glioblastoma cells after KA treatment for $48 \mathrm{~h}$}

The relative miRNA levels of the miR-21 anti-apoptotic gene were quantified in untreated U87 human glioblastoma cells and in cells treated with $70 \mu \mathrm{M} \mathrm{KA}$ for $48 \mathrm{~h}$. We

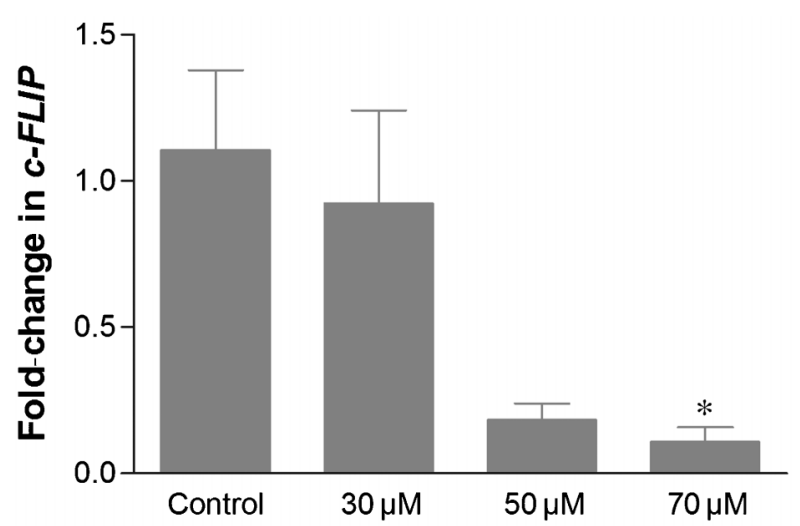

Figure 5. c-FLIP gene expression in U87 cells. The y-axis indicates the fold-change in c-FLIP expression. Data are reported as means \pm SD for 3 measurements. The expression of $c$-FLIP was compared between cells that had been treated with different concentrations of kaurenoic acid (KA) for $48 \mathrm{~h}$ and untreated cells. ${ }^{*} \mathrm{P}<0.05$ for $70 \mu \mathrm{M} \mathrm{KA}$ treatment vs control cells (Bonferroni multiple comparison test). observed a decrease in miR-21 expression in U87 cells treated with $70 \mu \mathrm{M} \mathrm{KA}$ for $48 \mathrm{~h}$ compared to untreated cells $(P<0.01$; Figure 6$)$.

\section{Discussion}

Plant-derived compounds are known to exhibit a curative potential against many types of malignancies. Kaurenoic acid has been shown to have significant cytotoxic and anti-proliferative effects on tumor cell cultures (human breast cancer, human colon cancer and leukemia) (19). The present study demonstrates that KA has considerable cytotoxic and anti-proliferative actions on the U87 human glioblastoma cell line. Interestingly, the concentrations of KA used in the present investigation

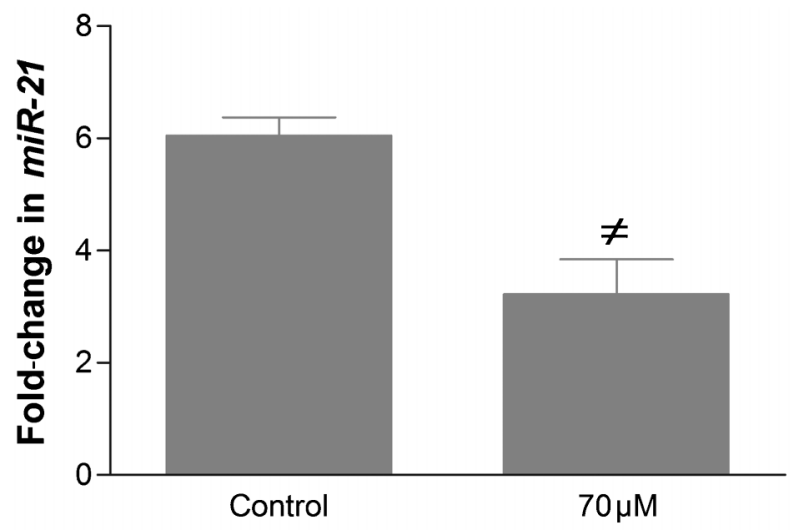

Figure 6. miR-21 gene expression in U87 cells. The y-axis indicates the fold-change in miR-21 expression. Data are reported as means \pm SD for 3 measurements. The expression of miR-21 was compared between cells that had been treated with $70 \mu \mathrm{M}$ kaurenoic acid (KA) for $48 \mathrm{~h}$ and untreated cells. ${ }^{7} \mathrm{P}<0.01$ for $70 \mu \mathrm{M}$ KA treatment $v s$ control cells (Bonferroni multiple comparison test). 
were previously reported to not exert cytotoxic effects on fibroblasts (9). Moreover, in the present study, we investigated the involvement of pro-apoptotic signals in U87 cells that were treated with KA. Apoptotic signaling can occur by two different pathways: the death receptorassociated extrinsic pathway and the mitochondriadependent intrinsic pathway. Fas is a cell surface death receptor and a member of the tumor necrosis factor receptor (TNFR) family. The Fas death receptor triggers apoptotic signals by binding to its cognate ligand, FasL (CD95L), and recruiting the adaptor molecule Fasassociated death domain protein (FADD). This subsequently results in the formation of the death-inducing signaling complex (DISC) and the activation of procaspase-8. There is also evidence supporting the idea that kaurene diterpene-induced apoptosis involves pathways that are dependent upon death receptors, including Fas and TNFR. Although some studies have shown that the up-regulation of Fas levels may be one of the mechanisms responsible for drug-induced apoptosis in a variety of cancers, no variation of Fas expression upon treatment was observed in the present study (20-22).

The caspases are a family of intracellular cysteine proteases with specificity for aspartic acid residues. Two of these cysteine proteases, referred to as "initiator" and "effector" caspases, play important roles in the apoptotic process. Previous reports have indicated that the apoptotic signal is transmitted through the activation of caspase- 8 in the death receptor route or the activation of caspase- 9 in the mitochondrial route (23). Recently, the mechanism of caspase- 8 activation has been investigated in greater detail. The mechanism of caspase- 8 activation by kaurene diterpenes is considered to involve three signaling pathways. The first of these is a death receptordependent pathway, the second is a $\mathrm{p} 38^{\mathrm{MAPK}}$-dependent pathway, and the third is a caspase-dependent pathway. Schrantz et al. (24) reported that $\mathrm{p} 38^{\mathrm{MAPK}}$ could activate caspase- 8 during transforming growth factor $\beta$-induced apoptosis, and Castrillo et al. (25) reported that kaurene diterpenes could modulate $\mathrm{p} 38^{\mathrm{MAPK}}$ activity. In the present study, the treatment of U87 glioblastoma cells with different concentrations of KA for $48 \mathrm{~h}$ resulted in elevated mRNA levels of caspase-8. These results suggest that KA induces apoptosis through the activation of caspase- 8 by either the death receptor route or the mitochondrial route. Further experiments focusing on the involvement of $\mathrm{p} 38^{\mathrm{MAPK}}$ activation in kaurene diterpeneinduced caspase- 8 activation are necessary. Such experiments will be useful in increasing our understanding of the apoptotic machinery that is activated during kaurene diterpene-induced apoptosis.

Caspase-3 is one of the most important downstream executioner caspases, and is capable of cleaving many important cellular substrates. Caspase-3-mediated cell death plays an important role in both the pathogenesis and treatment of a variety of malignancies (12). We found that the treatment of U87 cells with different concentrations of KA for $48 \mathrm{~h}$ led to increased mRNA levels of caspase-3. Several groups of investigators have reported that kaurene diterpene treatment led to caspase3 activation and apoptosis in human glioblastoma cell lines and human leukemia cells (26-28).

Cellular FADD-like interleukin-1 $\beta$-converting enzyme inhibitory protein $(c-F L I P)$, an anti-apoptotic protein, was recently reported to be recruited to the DISC. Once recruited, $c-F L I P$ was shown to interrupt the amino terminal effector domain-amino terminal effector domain (DEDDED) interaction between Fas-associated death domain (Fas) and caspase-8. This disruption resulted in an inhibition of Fas-mediated apoptosis. Two c-FLIP isoforms have been detected in human tissues: the long isoform ( $c$ $\left.F L I P_{L}\right)$ and the short form $\left(c-F L I P_{S}\right) . C-F L I P_{L}$ is structurally similar to caspase-8. It contains two DEDs and a caspaselike domain that lacks catalytic activity due to replacement of the active-central tyrosine with a cysteine. The short form, $c-F L I P_{s}$, contains two DEDs but lacks the caspaselike domain. Both forms of $c-F L I P$ are recruited to the DISC, and they inhibit apoptosis that is induced by FasL and tumor necrosis factor-related apoptosis inducing ligand (TRAIL) (29-32). Our present research shows that the treatment of U87 cells with different concentrations of KA for $48 \mathrm{~h}$ led to an increase in the mRNA level of $c$-FLIP. Therefore, c-FLIP may be involved in the resistance of tumors to apoptosis by modulating either receptor-induced apoptosis or phosphorylation events. In addition, tumor cells may exhibit resistance to apoptosis due to variations in their expression of $c-F L I P$. Interestingly, the drug-based targeting of phosphorylation events is considered to be a potent approach to restoring the susceptibility of tumor cells to apoptosis.

The emerging significance of miRNAs in cancer has resulted in a recent spike in interest in these unique RNAs. This increased interest has resulted in numerous profiling studies that aimed to assess the role of miRNAs in cancer. The cellular mechanisms that control apoptosis, cell growth and the cell cycle are efficient fail-safe mechanisms that prevent cancer development, despite the trillions of somatic cell division events that occur during a human lifetime. Therefore, cancer cells can only survive if the apoptotic response is dampened or disrupted, cell cycle checkpoints are evaded, and unrestricted cell proliferation is allowed to occur. Recent studies have shown that aberrant increased expression of miR-21 in glioblastoma cell lines may result in the downregulation of mRNAs that encode apoptosis-related genes. Thus, our data indicate that miR-21 also acts as an anti-apoptotic factor in KA-treated glioblastoma cells. These data suggest that miR-21 could act as a key factor in the resistance of glioma cells to apoptosis and that KA may be useful in cancer therapy $(15,33)$.

Malignant gliomas with an astrocytic lineage, including astrocytomas, anaplastic astrocytomas, and glioblas- 
tomas, are the most common human primary brain tumors. Despite intensive research over the last decade, the most current treatment modalities can only modestly improve patient survival (34). Therefore, finding new drugs and effective therapies for the clinical treatment of glioblastoma multiforme will remain an important area of research.

We found that KA possesses interesting properties with regard to its apoptosis-inducing mechanism. Most

\section{References}

1. Kleihues $P$, Louis DN, Scheithauer BW, Rorke LB, Reifenberger G, Burger PC, et al. The WHO classification of tumors of the nervous system. J Neuropathol Exp Neurol 2002; 61: 215-225.

2. Maher EA, Furnari FB, Bachoo RM, Rowitch DH, Louis DN, Cavenee WK, et al. Malignant glioma: genetics and biology of a grave matter. Genes Dev 2001; 15: 1311-1333, doi: 10.1101/gad.891601.

3. Bogler O, Weller M. Apoptosis in gliomas, and its role in their current and future treatment. Front Biosci 2002; 7: e339-e353, doi: 10.2741/bogler.

4. Boon $\mathrm{H}$, Wong J. Botanical medicine and cancer: a review of the safety and efficacy. Expert Opin Pharmacother 2004; 5: 2485-2501, doi: 10.1517/14656566.5.12.2485.

5. Ghisalberti EL. The biological activity of naturally occurring kaurene diterpenes. Fitoterapia 1997; 68: 303-325.

6. Slimestad R, Marston A, Mavi S, Hostettmann K. Larvicidal constituents of Melantheria albinervia. Planta Med 1995; 61: 562-563, doi: 10.1055/s-2006-959374.

7. Mitscher LA, Rao GS, Veysoglu T, Drake S, Haas T. Isolation and identification of trachyloban-19-oic and (-)kaur-16-en-19-oic acids as antimicrobial agents from the prairie sunflower, Helianthus annuus. J Nat Prod 1983; 46: 745-746, doi: 10.1021/np50029a024.

8. Mongelli E, Pomilio AB, Sanchez JB, Guerra FM, Massanet GM. ent-Kaur-16-en-19-oic acid, a KB cells cytotoxic diterpenoid from Elaeoselinum foetidum. Phytother Res 2002; 16: 387-388, doi: 10.1002/ptr.955.

9. Cavalcanti BC, Costa-Lotufo LV, Moraes MO, Burbano RR, Silveira ER, Cunha KM, et al. Genotoxicity evaluation of kaurenoic acid, a bioactive diterpenoid present in Copaiba oil. Food Chem Toxicol 2006; 44: 388-392, doi: 10.1016/ j.fct.2005.08.011

10. Rossi D, Gaidano G. Messengers of cell death: apoptotic signaling in health and disease. Haematologica 2003; 88: 212-218.

11. Tsuruo $T$, Naito $M$, Tomida A, Fujita $N$, Mashima $T$, Sakamoto $\mathrm{H}$, et al. Molecular targeting therapy of cancer: drug resistance, apoptosis and survival signal. Cancer Sci 2003; 94: 15-21, doi: 10.1111/j.1349-7006.2003.tb01345.x.

12. Debatin KM. Apoptosis pathways in cancer and cancer therapy. Cancer Immunol Immunother 2004; 53: 153-159, doi: 10.1007/s00262-003-0474-8

13. Yinjun L, Jie J, Weilai $X$, Xiangming $T$. Homoharringtonine mediates myeloid cell apoptosis via upregulation of proapoptotic bax and inducing caspase-3-mediated cleavage of poly(ADP-ribose) polymerase (PARP). Am J Hematol 2004; 76: 199-204, doi: 10.1002/ajh.20100. chemotherapeutic agents exhibit only pro-apoptotic effects. In U87 cells, KA has an effect on the regulation of several genes involved in the apoptotic pathway, including $c-F L I P$, caspase 3 , caspase 8 , and miR-21, and KA treatment results in decreased cell viability. Further experiments will be necessary to determine if KA may be useful as a lead compound for the development of new chemotherapeutic drugs for the treatment of primary brain tumors.

14. Bartel DP. MicroRNAs: genomics, biogenesis, mechanism, and function. Cell 2004; 116: 281-297, doi: 10.1016/S00928674(04)00045-5.

15. Chan JA, Krichevsky AM, Kosik KS. MicroRNA-21 is an antiapoptotic factor in human glioblastoma cells. Cancer Res 2005; 65: 6029-6033, doi: 10.1158/0008-5472.CAN-050137.

16. Pelletier SW, Chokshi HP, Desai HK. Separation of diterpenoid alkaloid mixtures using vacuum liquid chromatography. J Nat Prod 1986; 49: 892-900, doi: 10.1021/ np50047a021.

17. Kuwada SK, Scaife CL, Kuang J, Li X, Wong RF, Florell SR, et al. Effects of trastuzumab on epidermal growth factor receptor-dependent and -independent human colon cancer cells. Int J Cancer 2004; 109: 291-301, doi: 10.1002/ ijc. 11686

18. Ohba S, Hirose $\mathrm{Y}$, Yoshida K, Yazaki T, Kawase $\mathrm{T}$. Inhibition of $90-\mathrm{kD}$ heat shock protein potentiates the cytotoxicity of chemotherapeutic agents in human glioma cells. J Neurosurg 2010; 112: 33-42, doi: 10.3171/2009.3. JNS081146

19. Ambrosio SR, Schorr K, Da Costa FB. Terpenoids of Viguiera arenaria (Asteraceae). Biochem System Ecol 2004; 32: 221-224, doi: 10.1016/S0305-1978(03)00139-X.

20. White M, Mccubrey J. Suppression of apoptosis: role in cell growth and neoplasia. Leukemia 2001; 15: 1011-1021, doi: 10.1038/sj.leu.2402143.

21. Bergeron S, Beauchemin M, Bertrand R. Camptothecinand etoposide-induced apoptosis in human leukemia cells is independent of cell death receptor- 3 and -4 aggregation but accelerates tumor necrosis factor-related apoptosis-inducing ligand-mediated cell death. Mol Cancer Ther 2004; 3: 1659-1669.

22. Malugin A, Kopeckova P, Kopecek J. HPMA copolymerbound doxorubicin induces apoptosis in human ovarian carcinoma cells by a Fas-independent pathway. Mol Pharm 2004; 1: 174-182, doi: 10.1021/mp049967q.

23. Hengartner MO. The biochemistry of apoptosis. Nature 2000; 407: 770-776, doi: 10.1038/35037710.

24. Schrantz N, Bourgeade MF, Mouhamad S, Leca G, Sharma $\mathrm{S}$, Vazquez A. p38-mediated regulation of an Fas-associated death domain protein-independent pathway leading to caspase-8 activation during TGFbeta-induced apoptosis in human Burkitt lymphoma B cells BL41. Mol Biol Cell 2001; 12: 3139-3151.

25. Castrillo A, de Las Heras B, Hortelano S, Rodriguez B, Villar A, Bosca L. Inhibition of the nuclear factor kappa B (NFkappa B) pathway by tetracyclic kaurene diterpenes in 
macrophages. Specific effects on NF-kappa B-inducing kinase activity and on the coordinate activation of ERK and p38 MAPK. J Biol Chem 2001; 276: 15854-15860, doi: 10.1074/jbc.M100010200.

26. Ray SK, Patel SJ, Welsh CT, Wilford GG, Hogan EL, Banik NL. Molecular evidence of apoptotic death in malignant brain tumors including glioblastoma multiform: upregulation of calpain and caspase 3. J Neurosci Res 2002; 69: 197206, doi: 10.1002/jnr.10265.

27. Kondoh M, Suzuki I, Sato M, Nagashima F, Simizu S, Harada $\mathrm{M}$, et al. Kaurene diterpene induces apoptosis in human leukemia cells partly through a caspase-8-dependent pathway. J Pharmacol Exp Ther 2004; 311: 115-122, doi: 10.1124/jpet.104.069690.

28. Karmakar S, Banik NL, Ray SK. Curcumin suppressed antiapoptotic signals and activated cysteine proteases for apoptosis in human malignant glioblastoma U87MG cells. Neurochem Res 2007; 32: 2103-2113, doi: 10.1007/ s11064-007-9376-z.

29. Krueger A, Schmitz I, Baumann S, Krammer PH, Kirchhoff S. Cellular FLICE-inhibitory protein splice variants inhibit different steps of caspase-8 activation at the CD95 death-inducing signaling complex. J Biol Chem 2001; 276: 20633-20640, doi: 10.1074/jbc.M101780200.

30. Golks A, Brenner D, Krammer PH, Lavrik IN. The c-FLIP$\mathrm{NH} 2$ terminus (p22-FLIP) induces NF-kappaB activation. $J$ Exp Med 2006; 203: 1295-1305, doi: 10.1084/ jem.20051556

31. Day TW, Najafi F, Wu CH, Safa AR. Cellular FLICE-like inhibitory protein (c-FLIP): a novel target for Taxol-induced apoptosis. Biochem Pharmacol 2006; 71: 1551-1561, doi: 10.1016/j.bcp.2006.02.015.

32. Panner A, James CD, Berger MS, Pieper RO. mTOR controls FLIPS translation and TRAIL sensitivity in glioblastoma multiforme cells. Mol Cell Biol 2005; 25: 88098823, doi: 10.1128/MCB.25.20.8809-8823.2005.

33. Papagiannakopoulos T, Shapiro A, Kosik KS. MicroRNA-21 targets a network of key tumor-suppressive pathways in glioblastoma cells. Cancer Res 2008; 68: 8164-8172, doi: 10.1158/0008-5472.CAN-08-1305.

34. Castro MG, Cowen R, Williamson IK, David A, JimenezDalmaroni MJ, Yuan X, et al. Current and future strategies for the treatment of malignant brain tumors. Pharmacol Ther 2003; 98: 71-108, doi: 10.1016/S0163-7258(03)00014-7. 